\title{
Modelling of wind, hydroelectric and thermal power plant coordinated dispatch in Latvian power system
}

\author{
Olegs Linkevics (Associate professor, RTU EEF), Anatolijs Mahnitko (Professor, RTU EEF), Karina Mjadjuta \\ (Researcher, RTU EEF), Maris Balodis (Research and Development director, Latvenergo)
}

\begin{abstract}
Liberalization and restructuring of power sector changes the task of power system control substantially. Efficient control of operating regimes becomes especially important in competitive markets.

This paper provides a formulation of optimal control task, describes a simplified model for simulation of four different energy sources, consider a solution for optimization task in the numerical example and evaluates the impact of key parameters for selection of optimal regime.

For determination of optimal solution, the following methods of mathematical programming are applied: dynamic programming - for efficient use of hydroelectric resources, linear programming - for optimization of other power plants and import. Utilization of mentioned methods guarantees the acquisition of global optimum.
\end{abstract}

Keywords - optimization, unit commitment, coordinated dispatch, cost minimization, dynamic programming, linear programming.

\section{INTRODUCTION}

Restructuring of power sector, market liberalization, wider use of renewable energy resources and cogeneration changes the task of power system control substantially. Modern power systems are unbundled legally and by ownership, which obviously means a simplification of control task. At the same time, close relations, technical links and mutual interdependence of separate entities in selection of regimes and parameters still remains. For example, it is essential to take peculiarities of operating modes, parameters and constraints of neighboring power systems and independent power producers. Very often this information is considered to be confidential and is not available for planners in a given power system.

It is also necessary to take a stochastic nature of the task into account. Utilization of renewable energy resources (solar, wind, hydro) and cogeneration substantially increases influence of probabilistic variables (meteo conditions, consumer loads, etc.) to functioning of power system.

Presence of uncertain and conjectural parameters in power system control task, bring us to necessity to change the formulation and solution methods of the optimization task. That is why, it is possible to declare, that the task under consideration still relates to complicated and its solution requires consideration of specific circumstances and nontrivial approaches to task simplification and selection of control actions. Still an important role belongs to the operator of transmission system that is why an efficiency of power system control is dependent from an experience and qualification of personnel. The impact of subjective factors could be reduced essentially by utilization of special software for solution of optimization tasks. This paper is dedicated to synthesis of such software. Taken into account the complexity of considered task, deliberately some simplifications were accepted. The paper also considers main components of the software, used methodologies and algorithms.

The paper consists of 6 chapters and conclusions. The second chapter describes the task of operational control. The third chapter provides a simplified model of power system, the forth part is dedicated to mathematical formulation of optimization task and objective function. The calculation algorithm is synthesized in the fifth part, but calculation results are considered in the sixth chapter.

\section{SIMULATION OF OPERATING REGIMES OF POWER PLANTS}

From modelling point of view, Latvian power system has a relatively complicated structure of generating sources with features not typical to other power systems. Generation portfolio of Latvian power system includes a cascade of hydro power plants (HPP) with insignificant water reservoirs (pools). These run-of-river HPPs are operated in coordination and used mostly for covering of peak loads. There are also combined cycle gas turbine (CCGT) combined heat and power (CHP) plants, which are mostly operated in cogeneration mode, but are capable to run in condensing mode as well. In the future Latvian generation portfolio could be supplemented by base load capacity from nuclear power plant in Lithuania and by off-shore wind park with hardly predictable power output.

To model such a sophisticated generating system, it is necessary to use software capable to simulate a coordinated hydro-thermal dispatch, optimize heat and electricity production of CHP plants and take into account peculiarities of CCGT and wind park operation.

Potential benefits from application of such software are the following: 1) optimal loading of equipment, 2) fuel savings and reduction of $\mathrm{CO}_{2}$ emissions, 3) efficient utilization of water resources, 4) lower energy production costs, better competitiveness, 5) reduction of personnel errors, and better knowledge of equipment.

The proposed software (Fig. 1) simulates operating regimes of power plants, taking into account certain technical limitations (such as capacity limitations, water availability in the pool, emission allowance, planned maintenance and unplanned outages) and market constraints (such as energy demand and price projections).

The software is running a system optimization and scenario analysis by calculating optimal unit commitment and dispatch, synthesizes electricity and heat production program, evaluates the need for auxiliary services, produce optimal maintenance 
schedules, develop optimal electricity trading strategy with bid prices and volumes, estimates optimal fuel purchase schedule.

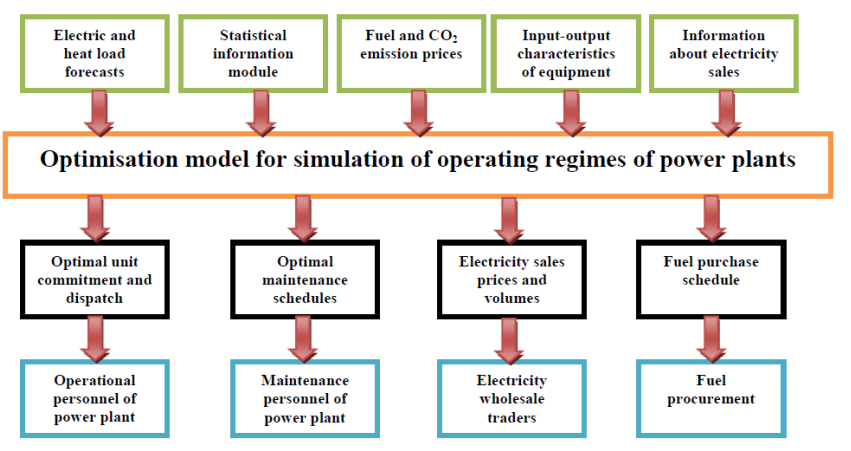

Fig. 1. Overall structure of optimization model

The software for simulation of operating regimes of power plants could be used both for short-term and long-term planning exercises. Short-term applications are related to dayahead market modelling and current day rescheduling, in case of large deviations from agreed schedule.

Long-term applications are associated with longer-term electricity trading decisions (for forward and futures markets), optimal maintenance schedules, fuel and $\mathrm{CO} 2$ emission allowance purchase. It also could be used for developing of justification for reconstruction and new build projects.

Very often this software is used together with commercial accounting system, which provides a feed-back (input data) for planning program, in order to calibrate and enhanced existing database.

\section{DESCRIPTION OF SIMPLIFIED MODEL}

Real scale power system model is very complicated and associated with development of complex algorithm, which requires substantial computer resources. This paper considers a simplified model of power system in order to verify proposed methods and test the algorithm.

Developed mathematical model simulates a power system, which consist of four generating units: hydroelectric unit, wind power, thermal power plant and foreign balancing unit (import). The optimization task is to create a balance of active power and load, by securing optimal distribution of electric loads between mentioned generating sources. Optimal unit commitment and unit dispatch has its optimality criteria, defined as a profit maximization or cost minimization. In our example it is the second option.

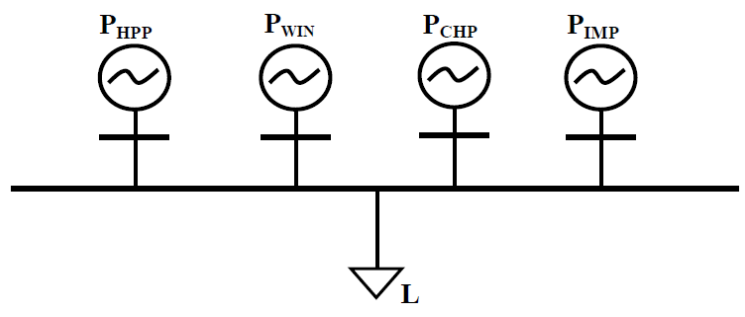

Fig. 2. Scheme of simplified model
The simplified model (Fig. 2) consists of four generating units: hydroelectric $\mathrm{P}_{\mathrm{HPP}}=6 * 67=402 \mathrm{MW}$ (6 hydro units with capacity $67 \mathrm{MW}), \mathrm{CHP}$ unit $\mathrm{P}_{\mathrm{TEC}}=428 \mathrm{MW}, \mathrm{Q}_{\mathrm{TEC}}=0 \mathrm{MW}$ (CHP is operated in condensing mode, heat energy is not produced), wind power $\mathrm{P}_{\mathrm{WIND}}=2 \mathrm{MW} * 200=400 \mathrm{MW}$, foreign balancing unit $\mathrm{P}_{\mathrm{IMP}}=500 \mathrm{MW}$. Electricity from all generators is supplied to a single network node, to which electricity consumers are connected.

Peak load of electricity consumers is $\mathrm{L}=1220 \mathrm{MW}$. Electricity trading is implemented in SPOT market, where electricity price is changing every hour.

Optimization is implemented for one business day period (24 hours) with modelling interval of 1 hour. Minimal cost criteria is met for every hour, every generating unit and for the whole system, such looking for the optimal economical solution.

\section{OVERALL FORMULATION OF THE OBJECTIVE FUNCTION}

Nowadays, a popular criterion for optimization of electricity production is profit maximization. At the same time, it is obvious, that maximum profit could be obtained, when production costs are minimized. That is why, for optimization of simplified power system, based on four generating sources, we suggest applying cost minimization criterion:

$$
C(t) \rightarrow \min
$$

Total costs of electricity production for the power system under consideration, consists of $\mathrm{C}_{\mathrm{HPP}}$ - operation and maintenance $(\mathrm{O} \& \mathrm{M})$ costs of hydroelectric unit, $\mathrm{C}_{\mathrm{WIND}}-\mathrm{O} \& \mathrm{M}$ costs of wind park, $\mathrm{C}_{\mathrm{CHP}}$ - fuel and O\&M costs of CHP plant and $\mathrm{C}_{\mathrm{IMP}}$ - costs of imported electricity.

$$
C^{(t)}=C^{(t)}{ }_{H P P}+C^{(t)}{ }_{W I N D}+C^{(t)}{ }_{C H P}+C^{(t)}{ }_{I M P}
$$

Operation and maintenance costs of hydroelectric unit are calculated as following:

$$
C^{(t)}{ }_{H P P}=P^{(t)}{ }_{H P P} * C_{H P P}
$$

where $\mathrm{P}^{(\mathrm{t})}{ }_{\mathrm{HPP}}$ - capacity of hydroelectric unit at t-hour, $\mathrm{MW}, \mathrm{C}_{\mathrm{HPP}}$ - variable costs of electricity production (EUR/MW) of hydroelectric unit - costs, which are depends on electricity production volumes. O\&M costs of hydroelectric unit include operation costs, maintenances costs and depreciation.

Operation and maintenance costs of Wind Park:

$$
C^{(t)}{ }_{W I N D}=P^{(t)}{ }_{\text {WIND }} * C_{\text {WIND }}
$$

where $\mathrm{P}^{(\mathrm{t})}{ }_{\text {WIND }}$ - electric capacity of wind park at t-hour, $\mathrm{MW}, \mathrm{C}_{\text {WIND }}$ - variable costs of electricity production at wind park, EUR/MW.

Total costs of electricity production in CHP plant are calculated as following:

$$
C_{C H P}^{(t)}=\left(P_{C H P}^{(t)} / \eta_{C H P}\right) * C_{B}+P^{(t)}{ }_{C H P} * C_{C H P \_O \& M}
$$

where $\mathrm{P}^{(\mathrm{t})}$ CHP - electric capacity of CHP plant at t-hour, $\mathrm{MW}, \eta_{\mathrm{CHP}}-$ fuel utilisation efficiency of $\mathrm{CHP}$ plant, $\%$, $\mathrm{C}_{\mathrm{B}}$ - fuel costs, EUR/MW, $\mathrm{C}_{\mathrm{CHP} \_\mathrm{O} \& \mathrm{M}}$ - variable costs of electricity production of CHP plant, EUR/MW. 
Cost of electricity import could be calculated using the formula:

$$
C^{(t)}{ }_{I M P}=P^{(t)}{ }_{I M P} * \pi^{(t)}{ }_{I M P}
$$

where $\mathrm{P}^{(\mathrm{t})}{ }_{\mathrm{IMP}}$ - capacity of electricity import at t-hour, MW, $\pi_{\text {IMP }}^{(\mathrm{t})}$ - electricity market price at t-hour, EUR/MW.

Electricity market (SPOT) price $\pi^{(\mathrm{t})}$ IMP is determined in electricity power exchange for every hour of day ahead. It is assumed, that producers has low influence on electricity market prices.

During the optimization process, it is necessary to take certain constraints into account. These constraints are associated with technical characteristics of generating units and special requirements, such environmental restrictions. Constraints could be classified as global and local constraints.

Provision of electricity balance (active power) belongs to global constraints of optimization task:

$$
L^{(t)}=P^{(t)}{ }_{H P P}+P^{(t)}{ }_{W I N D}+P^{(t)}{ }_{C H P}+P^{(t)}{ }_{I M P}
$$

where $\mathrm{L}^{(\mathrm{t})}$ - electric load of the system at t-hour, MW.

Local constraints of optimization task are associated with technical performance and installed capacity of generating units. Operation of CHP plant is constrained by the maximum and minimum allowed power output (capacity), where operation of the unit is stable and efficient:

$$
P_{C H P}^{\min } \leq P_{C H P} \leq P_{C H P}^{\max }
$$

Similarly, the effective capacity range is determined for hydroelectric unit:

$$
P_{H E S}^{\min } \leq P_{H E S} \leq P_{H E S}^{\max }
$$

For example, for Riga HPP maximum capacity of hydroelectric unit at water head of $18 \mathrm{~m}$ is $67.3 \mathrm{MW}$, while minimum loading (at the same water head) is $25.7 \mathrm{MW}(\sim 38 \%$ of nominal power). Operating of hydroelectric unit is also constrained by maximum and minimum water level at higher pool, as well as effective (usable) volume of water reservoir. For example, maximum level of Riga HPP at higher pool is 18 $\mathrm{m}$, while minimal level is $16 \mathrm{~m}$, which means that effective volume is $34600000 \mathrm{~m}^{3}$.

\section{ALGORITHMS AND SOLUTION METHODS FOR THE OPTIMIZATION PROBLEM}

Simplified optimization algorithm is started with initialization of calculation procedure by provision of input data into data arrays. Each value in the array corresponds to certain hour of 24 hour modelling period. Specifically, $\mathrm{P}_{\text {sum }}[\mathrm{]}$ - hourly electric loads for $24 \mathrm{~h}, \mathrm{MW}, \mathrm{P}_{\mathrm{CHPmax}}[\mathrm{]}$ - maximum available capacity of CHP plant at each hour, $\mathrm{P}_{\text {IMPmax }}[$ ] maximum available imported power at each hour, $\mathrm{C}_{\mathrm{IMP}}[\mathrm{]}-$ forecasted electricity price in the power exchange for each hour, QwIND [ ] - forecasted wind speed for each hour. Calculation is performed for every hour of day-ahead market (24 periods).

For solution of optimization problem, simplified optimization algorithm was developed and implemented (Fig. 3 ). The algorithm could be decomposed conditionally into three calculation blocks. In the first block, capacity of Wind Park is evaluated, based on wind conditions for particular hour.

Optimal water resource utilization schedule is looked for in the second calculation block. In this optimization process, the following data is processed by the model: hourly electric loads for 24 hour period, water inflow to hydro power plant, water level at higher pool, electricity and fuel costs. To find solution for this optimization task, a widely known method of dynamic programming was applied. The theory and application of this method was sufficiently described in the following literature sources [1], [2].

Linear programming method is used in the third calculation block to determine optimal loading of CHP plant and electricity import volumes for each hour of the day.

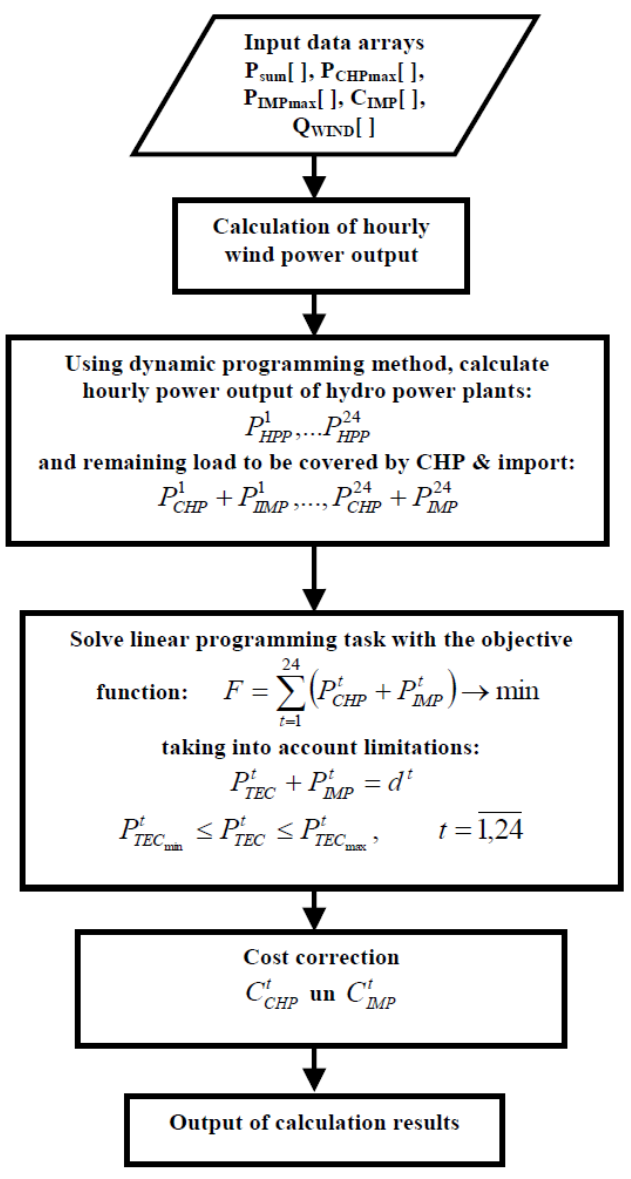

Fig. 3. Simplified optimization algorithm used in the model

The algorithm was implemented in C\# programming language. Developed mathematical model calculates optimal distribution of electric load among generating units and cost breakdown by generating source for each hour of modelling period.

For solution of the considered optimization task, other alternative solution methods, such as Monte Carlo method or Gaming Theory principles could be applied, which was sufficiently investigated in the following publications [3], [4], [5], [6] and [7]. 


\section{CAlCUlation Results}

To verify the proposed algorithm and mathematical model, calculations are made for the simplified power system, which consists of four generating units: hydroelectric unit, wind power, thermal power plant and foreign balancing unit (import). Least cost power production plan to cover hourly electricity demand (L) of the power system was obtained for the Base Case and other scenarios.

The following input data and assumptions are used for the Base Case calculations:

- Hourly average electric loads for the working day $\left(\mathrm{L}_{\mathrm{avg}}\right)$.

- For hydroelectric unit, water inflow was assumed 400 $\mathrm{m} 3 / \mathrm{s}$, water head - $18 \mathrm{~m}$, efficient (usable) volume of water pool - $34600000 \mathrm{~m}^{3}$. Variable electricity production cost of hydroelectric unit was assumed 7 EUR/MW.

- It is assumed, that wind park consists of 200 wind turbines Enercon E82. Power curve (as a function of wind speed) was approximated based on E82 characteristics. Wind conditions for 19.04.2009 are based on real wind measurements. Variable electricity production cost of wind park was assumed 5 EUR/MW.

- Input-output characteristics of combined cycle gas turbine (CCGT) CHP unit for the condensing mode of operation was used. Natural gas price was assumed 25 EUR/MW, while variable electricity production cost 2.5 EUR/MW

- Hourly electricity prices of import power are based on information from Nordpool power exchange (Estonian price area) for 17.01.2012.

Optimal solution for the Base Case scenario was found with application of developed mathematical model. The results of these calculations are analyzed below. Figure 4 illustrates optimal distribution of electric load between power generating units in the Base Case scenario.

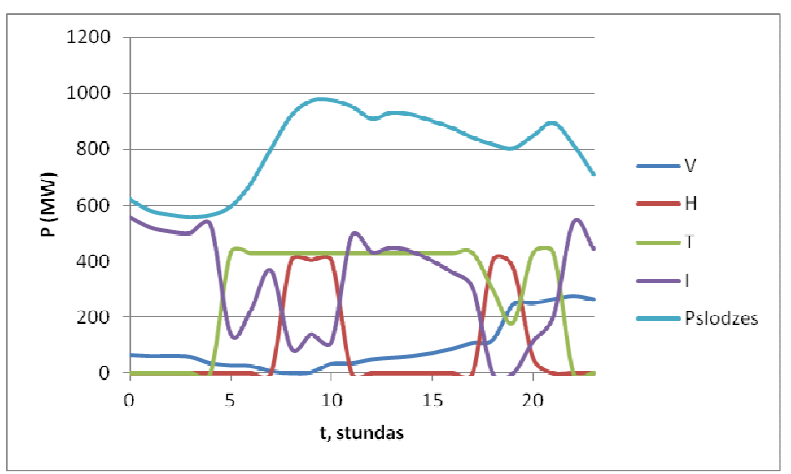

Fig. 4. Optimal distribution of electric load among generating units in the Base Case

From the Base Case calculations, we could make the following conclusions. Hydroelectric units, being the cheapest, but energy constrained units are operated to cover peak loads of the power system considered. Wind park is loaded subject to availability of wind resources. When cost of electricity production in thermal power plant (CHP) is lower, than import (during the day), it is operated at full power, otherwise it is constrained. The import is used as a balancing power to the extent, which is determined by its competitiveness with CHP unit.

Table 1 represents a cost breakdown by generating source in the Base Case situation. Overall electricity production costs are estimated approximately 713081 EUR with contribution of CHP 49\%, import power - 47\%, wind and hydroelectric approximately $2 \%$ (each).

TABLE I

COST BREAKDOWN BY GENERATING SOURCE IN THE BASE CASE SCENARIO

\begin{tabular}{|c|r|r|r|r|r|}
\hline Hour & $C_{\text {WIND }}$ & \multicolumn{1}{c|}{$C_{\text {HPP }}$} & \multicolumn{1}{c|}{ C $_{\text {CHP }}$} & \multicolumn{1}{c|}{ C $_{\text {MP }}$} & Csum \\
\hline 0 & 384 & 0 & 2658 & 21260 & 24302 \\
\hline 1 & 360 & 0 & 2658 & 20828 & 23846 \\
\hline 2 & 360 & 0 & 2658 & 19976 & 22994 \\
\hline 3 & 342 & 0 & 2658 & 19729 & 22728 \\
\hline 4 & 204 & 0 & 2658 & 20908 & 23769 \\
\hline 5 & 156 & 0 & 20291 & 6063 & 26511 \\
\hline 6 & 144 & 0 & 20291 & 9854 & 30289 \\
\hline 7 & 36 & 0 & 20291 & 16670 & 36998 \\
\hline 8 & 0 & 2814 & 20291 & 4176 & 27281 \\
\hline 9 & 18 & 2814 & 20291 & 6580 & 29703 \\
\hline 10 & 192 & 2814 & 20291 & 5288 & 28586 \\
\hline 11 & 204 & 0 & 20291 & 22881 & 43376 \\
\hline 12 & 288 & 0 & 20291 & 20224 & 40804 \\
\hline 13 & 324 & 0 & 20291 & 21105 & 41720 \\
\hline 14 & 360 & 0 & 20291 & 20271 & 40922 \\
\hline 15 & 426 & 0 & 20291 & 18733 & 39451 \\
\hline 16 & 522 & 0 & 20291 & 16426 & 37239 \\
\hline 17 & 648 & 0 & 20291 & 14045 & 34985 \\
\hline 18 & 714 & 2814 & 14894 & 0 & 18422 \\
\hline 19 & 1476 & 2646 & 10074 & 0 & 14196 \\
\hline 20 & 1512 & 371 & 20291 & 5081 & 27255 \\
\hline 21 & 1584 & 0 & 20291 & 8628 & 30503 \\
\hline 22 & 1656 & 0 & 2658 & 21654 & 25968 \\
\hline 23 & 1584 & 0 & 2658 & 16993 & 21234 \\
\hline$\Sigma$ & 13494 & 14273 & 347942 & 337371 & 713081 \\
\hline & & & & & \\
\hline
\end{tabular}

Summary of other calculation scenarios is given in table 2 .

TABLE II

SUMMARY OF CALCULATION SCENARIOS

\begin{tabular}{|c|c|}
\hline Scenario 1 & $\begin{array}{l}\text { Represents power system at spring flood period, when } \\
\text { water inflow at hydroelectric unit is } 2800 \mathrm{~m}^{3} / \mathrm{s} \text { (water } \\
\text { inflow determines the output of hydro). Other input } \\
\text { data and assumptions are the same as in the Base Case } \\
\text { scenario. }\end{array}$ \\
\hline Scenario 2 & $\begin{array}{l}\text { Represents an extraordinary situation in the electricity } \\
\text { market, when electricity SPOT prices in power } \\
\text { exchange are extremely high (real situation in } \\
\text { Nordpool during the working day of } 01.02 .2012 \text {. Other } \\
\text { assumptions are the same. }\end{array}$ \\
\hline Scenario 3 & $\begin{array}{l}\text { Extremely high wind conditions with wind speed up to } \\
15 \mathrm{~m} / \mathrm{s} \text {. Real situation of } 21.11 .2009 . \text { Other } \\
\text { assumptions are the same. }\end{array}$ \\
\hline Scenario 4 & $\begin{array}{l}\text { Natural gas price increases from } 25 € / \mathrm{MW} \text { (in the Base } \\
\text { Case situation) to } 30 € / \mathrm{MW} \text {. As the result, high } \\
\text { electricity production cost at CHP plant. Other input } \\
\text { data and assumptions are the same as in the Base Case } \\
\text { scenario. }\end{array}$ \\
\hline
\end{tabular}

Analyzing different calculation scenarios (table 3 and 4), we draw the following conclusions. In the case, when natural gas prices increases from $25 € / \mathrm{MW}$ to $30 € / \mathrm{MW}, \mathrm{CHP}$ production cost become uncompetitive with import power, that is why CHP plant is shutdown. The share of import in this Scenario 4 is increasing approximately two times in comparison to the Base Case situation. 
TABLE III

ELECTRICITY PRODUCTION VOLUMES (MWH) BY GENERATING SOURCE BY SCENARIO

\begin{tabular}{|c|c|c|c|c|c|}
\hline Source & BWhe case & Scenario 1 & Scenario 2 & Scenario 3 & Scenario 4 \\
\hline Wind & 2249 & 2249 & 2249 & 9008 & 2249 \\
\hline Hydro & 2039 & 9648 & 2039 & 2039 & 2039 \\
\hline CHP & 6897 & 5834 & 7753 & 5138 & 0 \\
\hline Import & 7884 & 1338 & 7028 & 2884 & 14781 \\
\hline Total production & 19069 & 19069 & 19069 & 19069 & 19069 \\
\hline
\end{tabular}

TABLE IV

ELECTRICITY PRODUCTION COSTS (EUR) BY GENERATING SOURCE BY SCENARIO

\begin{tabular}{|c|c|c|c|c|c|}
\hline C $(\epsilon)$ & Base case & Scenario 1 & Scenario 2 & Scenario 3 & Scenario 4 \\
\hline Wind & 13494 & 13494 & 13494 & 54048 & 13494 \\
\hline Hydro & 14273 & 67536 & 14273 & 14273 & 14273 \\
\hline CHP & 347942 & 304147 & 383210 & 275472 & 76543 \\
\hline Import & 337371 & 56590 & 523311 & 118708 & 651169 \\
\hline Total costs & 713081 & 441767 & 1134288 & 462500 & 755480 \\
\hline
\end{tabular}

Comparing overall production costs (Fig. 5), it become obvious, that utilization of renewable energy sources, such as wind and hydro, with low marginal costs, reduces overall production costs. In the case of high water inflow (Scenario 1), hydroelectric units could be loaded to nominal capacity, operating as the base load plant and covering the half of the system demand. The same situation is in the case of extremely high wind conditions (Scenario 3), when wind power dominates in the system. Nevertheless, we shall take into account, that utilization of renewable energy resources in the power system is associated with certain constraints and uncertainty.

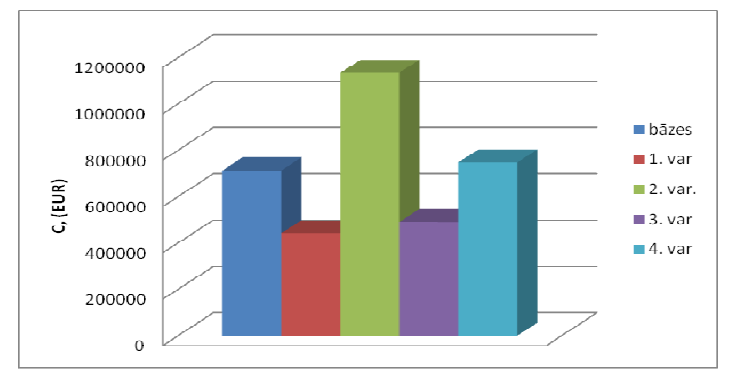

Fig. 5. Total costs of electricity production by scenario

\section{CONCLUSIONS}

The model of real power system is very complicated. Implementation of this model is associated with creation of a sophisticated algorithm and substantial computational resources. This paper however describes a simplified model of power system, just to verify the feasibility and functionality of the proposed methods and algorithms.

Developed mathematical model simulates a power system, which consists of four generating units: hydroelectric unit, wind power, thermal power plant and foreign balancing unit (import).

For determination of optimal solution, the following methods of mathematical programming are applied: dynamic programming - for efficient use of hydroelectric resources, linear programming - for optimization of other power plants and import. Utilization of mentioned methods guarantees the acquisition of global optimum

\section{REFERENCES}

[1] Gerhards J., Mahṇitko A. Energosistēmu režīmu optimizācija - Rīga: RTU, 2005.-248 lpp

[2] Gerhards J., Mahnitko A. Elektroapgādes sistēmu optimizācija - Rīga: RTU Izdevniecība, 2007.-149 lpp.

[3] Valdma M., Tammoja H., Keel M. Optimization of thermal power plants operation - Tallin: TUT Press, 2009.- 185 lpp.

[4] A.Sauhats, J.Jnde, G. Vempers, V.Neimane. On co-generation strategies in the cities of North-Eastern Europe. Paper presented for PowerTech 2007 International Conference in Lausanne, Switzerland, July 01-06. 2007. Paper submition \#59, p.6.

[5] Viktoria Neimane, Antans Sauhats, Guntars Vempers, Inga Tereskina, Galina Bochkarjova, Approach for Power Supply System Planning Based on Cooperative Game Theory, The 5th International Conference on the EUROPEAN ELECTRICITY MARKET - EEM 08, Lisbon, Portugal, May 28-30, 2008, ID\#260.

[6] V. Neimane, A. Sauhats, J. Inde, G. Vempers, G. Bockarjova. Using Cooperative Game Theory in energy Supply Planning Tasks, 16th Power Systems Computation Conference- PSCC2008, Glasgow, Scotland, July 14-18, 2008, ID\#220.

[7] V.Neimane, A.Sauhats, G.Vempers, I.Tereskina,G.Bockarjova 'Allocating production cost of CHP plant to heat and power based on cooperative game theory", The 6th International Conference on the EUROPEAN ELECTRICITY MARKET - EEM 09 , Leuven, Belgium, May 27-29, 2009.

\section{VIII.BIOGRAPHIES}

Olegs Linkevics was born in Jurmala, Latvia on December 27, 1973. He received Dipl. Eng., M.Sc and PhD degree from the Riga Technical University in 1994, 1996 and 2008 respectively.

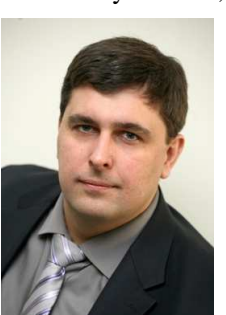

Since 2009, he is a Docent at Faculty of Electrical and Power engineering. He is teaching the introductory course "Basics of Electric and Heat Engineering" to the first year students in the Faculty of Electrical Engineering. Dr. Linkevics is participating in the scientific research work and supervising several students thesis for their bachelor and master degrees. In 2010 Olegs Linkevics was elected as the Associated Professor.

After graduation from Riga Technical university in $1995 \mathrm{Mr}$. Linkevics has started his career in Latvian national power utility AS Latvenergo. For 19 years of working experience in the company he has grown up from the Planning Engineer to the Head of Development in the Research \& Development department.

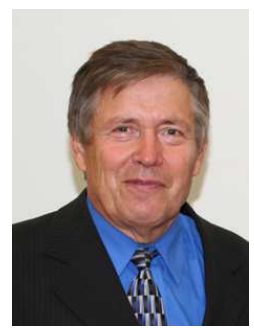

Anatoly Mahnitko was born in Dnepropetrovsk, Ukraine in 1942. He graduated from Mechanics and Mathematics Faculty of Kiev State University (Ukrane). In 1972 he received Ph.D. in the specialty of Electrical Engineering from Riga Technical University (RTU)

He has been working in RTU from 1972 as a senior lecturer, Assistant, Associate Professor and Professor of the Institute of Power Engineering. His research interests include Electric Power System Mathematical Simulation and Optimization, the electric power market problems.

Maris Balodis born in Dobele, Latvia on July 4, 1970. He received Dipl. Engineer in Electrical and Master Degree in Economics from the Riga

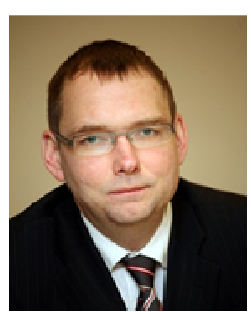
Technical University in 1993 and 1995 respectively. After graduation from Riga Technical University in $1993 \mathrm{Mr}$. Balodis has started his career in Latvian national power utility State JSC Latvenergo. Has 21 years of working experience in the company in various positions. Currently holding position of Director of Research \& Development. Mr. Balodis main competence is preparation of development programs and strategies, research and feasibility studies. 